\title{
Quantitative structure-activity relationship to predict the anti-malarial activity in a set of new imidazolopiperazines based on artificial neural networks
}

\author{
Saeed Yousefinejad ${ }^{1 *}$ (D, Marjan Mahboubifar ${ }^{2}$ and Rayhaneh Eskandari ${ }^{3}$
}

\begin{abstract}
Background: After years of efforts on the control of malaria, it remains as a most deadly infectious disease. A major problem for the available anti-malarial drugs is the occurrence of drug resistance in Plasmodium. Developing of new compounds or modification of existing anti-malarial drugs is an effective approach to face this challenge. Quantitative structure activity relationship (QSAR) modelling plays an important role in design and modification of anti-malarial compounds by estimation of the activity of the compounds.

Methods: In this research, the QSAR study was done on anti-malarial activity of 33 imidazolopiperazine compounds based on artificial neural networks (ANN). The structural descriptors of imidazolopiperazine molecules was used as the independents variables and their activity against 3D7 and W2 strains was used as the dependent variables. During modelling process, $70 \%$ of compound was used as the training and two 15\% of imidazolopiperazines were used as the validation and external test sets. In this work, stepwise multiple linear regression was applied as the valuable selection and ANN with Levenberg-Marquardt algorithm was utilized as an efficient non-linear approach to correlate between structural information of molecules and their anti-malarial activity.

Results: The sufficiency of the suggested method to estimate the anti-malarial activity of imidazolopiperazine compounds at two 3D7 and W2 strains was demonstrated using statistical parameters, such as correlation coefficient $\left(R^{2}\right)$, mean square error (MSE). For instance $R_{\text {train }}^{2}=0.947, R_{\text {val }}^{2}=0.959, R_{\text {test }}^{2}=0.920$ shows the potential of the suggested model for the prediction of 3D7 activity. Different statistical approaches such as and applicability domain (AD) and $y$-scrambling was also showed the validity of models.

Conclusion: QSAR can be an efficient way to virtual screening the molecules to design more efficient compounds with activity against malaria (3D7 and W2 strains). Imidazolopiperazines can be good candidates and change in the structure and functional groups can be done intelligently using QSAR approach to rich more efficient compounds with decreasing trial-error runs during synthesis.
\end{abstract}

Keywords: Antimalarial, Imidazolopiperazine, QSAR, Artificial neural networks

\footnotetext{
*Correspondence: yousefisa@sums.ac.ir; yousefinejad.s@gmail.com

${ }^{1}$ Research Center for Health Sciences, Institute of Health, Department of Occupational Health Engineering, School of Health, Shiraz University of Medical Sciences, Shiraz, Iran

Full list of author information is available at the end of the article
} 


\section{Background}

After years of efforts to fight and control of malaria, it is still a prevalent and deadly infectious disease, especially in the third-world countries in Africa, Asia, and South America $[1,2]$. The estimated deaths because of malaria in 2015 were 429,000 (range 235,000-639,000), which were mainly distributed in the Africa (92\%), Southwest Asia (6\%) and the Eastern Mediterranean (2\%) [3]. The pregnant women and children below 5 years of age are the more vulnerable groups, and about $85 \%$ of deaths occurring in children with this age range [4].

The disease is caused by a parasite of the genus Plasmodium. The main species of Plasmodium are Plasmodium falciparum, Plasmodium vivax, Plasmodium ovale, Plasmodium knowlesi and Plasmodium malariae, with P. falciparum responsible for most of the mortality $[1,4]$.

Many compounds with anti-malarial activity have been described, including quinine, chloroquine, proguanil, pyrimethamine, artemisinin, mefloquine, atovaquone [5]. The major problem in the treatment of malaria is that Plasmodium parasites become resistant to anti-malarial drugs. The most commonly used anti-malarial drug, chloroquine, became ineffective due to rapidly spreading resistance of $P$. falciparum to this compound; the newer anti-malarial drugs, such as mefloquine or artemisinins also face to resistance problem. The other problem in control of malaria is the lack of an effective vaccine for this disease. Therefore, developing new anti-malarial agents is a necessity and chemical modification of existing compounds is one of the strategies available [1].

In silico methods, such as quantitative structure activity relationship (QSAR), molecular docking and pharmacophore modelling by decreasing the time and cost of drug discovery play a significant role in the field of drug design and development [6]. QSAR can provide a mathematical relationship of the physicochemical properties and structural features that is required for a specific activity for a set of similar compounds. In this way, synthesis of potential candidate molecules can be performed by focusing on the chemical characteristics which have influenced on a specific activity [7].

QSAR methods have previously been used to investigate anti-malarial compounds. In 2001, Agrawal et al. studied the anti-malarial activity of a series of sulfonamide derivatives (2,4-diamino-6-quinazoline sulfonamides) [8]. In 2002, 3D-QSAR studies on the artemisinin analogues were performed by Cheng et al., a study done on the basis of the docking models employing comparative molecular force fields analysis (CoMFA) and comparative molecular similarity indices analysis (CoMSIA) [9]. Katritzky et al. investigated two various set of compounds for each of two strains D6 and NF54 of Plasmodium falciparum using QSAR modelling with CODESSA
PRO software in 2006 [10]. A study on anti-malarial artemisinin derivatives was done by Cardoso et al. in 2008 using molecular electrostatic potential (MEP) maps and multivariate QSAR [11]. In 2015, Ojha and Roy reported the status of anti-malarial drug research from the year 2011 to 2014 with special reference to application of QSAR models. In their report, aminoquinolines as a group of anti-malarial compounds were analysed by various research groups using QSAR models; the other groups of compounds were endochin analogs, artemisinin analogs, aurone chalcone, prodiginines, acridine, hydroxypyridinones and cycloguanil derivatives, which their QSAR modelling reported [7]. In 2018, Cheoymang and Na-Bangchang in a systematic review article reported about application of in silico models for antimalarial drug discovery in the years between 2008 and 2015. In this article 2D- or 3D-QSAR is mentioned as one of the commonly applied in silico methods for investigating on anti-malarial compounds [12].

Imidazolopiperazine is a class of anti-malarial compounds, including KAF156 (also known as GNF156) which is active against a wide range of Plasmodium species and in phase 2 trials have shown better or analogous parasite killing rates compared to the effective artemisinin-based combination therapy (ACT) [13, 14]. In this article, the anti-malarial activity of a set of imidazolopiperazines was investigated using quantitative structure activity relationship. Artificial neural networks were used for modelling the activity of 33 imidazolopiperazines derivatives.

\section{Methods \\ Data set}

A data set consisting of imidazolopiperazines reported by Wu et al. and Nagle et al. $[15,16]$ was used for this study. A set of 33 compounds was selected which their structural skeleton and the name of compounds are displayed in Table 1.

\section{Descriptor generation and pretreatment}

After drawing the 2D structures of the 33 imidazolopiperazine derivatives using HyperChem software (Ver. 8.0.3, Hypercube Inc., Gainesville, USA), the geometries of the molecules were fully optimized using the semiempirical AM1 method. The optimization was done until the root mean square gradient achieves $0.001 \mathrm{kcal} \mathrm{mol}^{-1}$ or 1000 cycles for all the molecular structures.

The resulting optimized geometries were transferred to the DRAGON software $[17,18]$, and the descriptors were calculated. Then, the same descriptors for all the structures were kept and others were removed. At the first step for pretreatment of the descriptors, the constant or near-constant variables among the remained 
Table 1 Structures of imidazolopiperazine derivatives and their biological activities (IC50, nM) for 3D7 and W2

\begin{tabular}{|c|c|c|}
\hline \multirow[t]{2}{*}{ No. } & \multirow[t]{2}{*}{ Name and structure of the compounds } & $\begin{array}{l}\text { P. falciparum } \\
\text { strain } \mathrm{IC}_{50} \\
(\mathrm{nM})\end{array}$ \\
\hline & & 3D7 \\
\hline
\end{tabular}

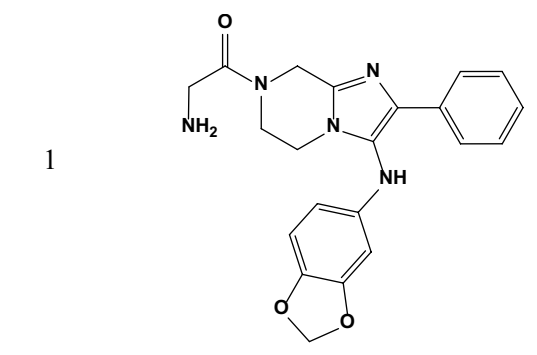

2-Amino-1-(3-

(benzo[d][1,3]dioxol-5-

ylamino)-2-phenyl-5,6dihydroimidazo[1,2- $\alpha]$ pyrazin-7(8H)-yl)-

ethanone

2

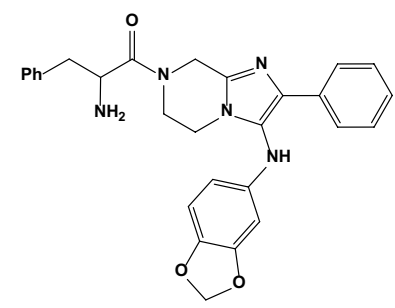

2-Amino-1-(3-

(benzo[d][1,3]dioxol-5-

ylamino)-2-phenyl-5,6dihydroimidazo[1,2- $\alpha$ ] pyrazin-7(8H)-yl)-

3-phenylpropan-1-one

2-Amino-1-(3(benzo[d][1,3]dioxol-5ylamino)-2-phenyl-5,6dihydroimidazo[1,2- $\alpha$ ] pyrazin-7(8H)-yl)-

4-methylpentan-1-one

4

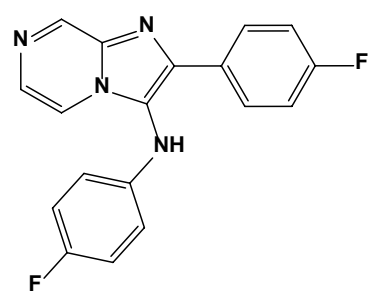

$\mathrm{N}, 2-\mathrm{Bis}(4-$

fluorophenyl)imidazo[1,2 - $\alpha$ ] pyrazin$>10 \quad 5520$

3-amine
5<smiles>Fc1ccc(Nc2c(-c3ccc(F)cc3)nc3n2CCNC3)cc1</smiles>

N,2-Bis(4-fluorophenyl)$5,6,7,8-$ tetrahydroimidazo[ 200 175 1,2- $\alpha$ pyrazin-3-amine 
Table 1 (continued)

No. $\quad$ Name and structure of the compounds $\begin{gathered}\begin{array}{c}\text { P. falciparum } \\ \text { strain } \mathrm{IC}_{50} \\ (\mathrm{nM})\end{array} \\ \begin{array}{c}\text { 2-Amino-1-(2-(4- } \\ \text { fluorophenyl)-3-(4- } \\ \text { fluorophenylamino)- }\end{array} \\ \begin{array}{r}\text { W,6-dihydroimidazo[1,2- } \\ \alpha] \text { pyrazin-7(8H)-yl)- }\end{array}\end{gathered}$

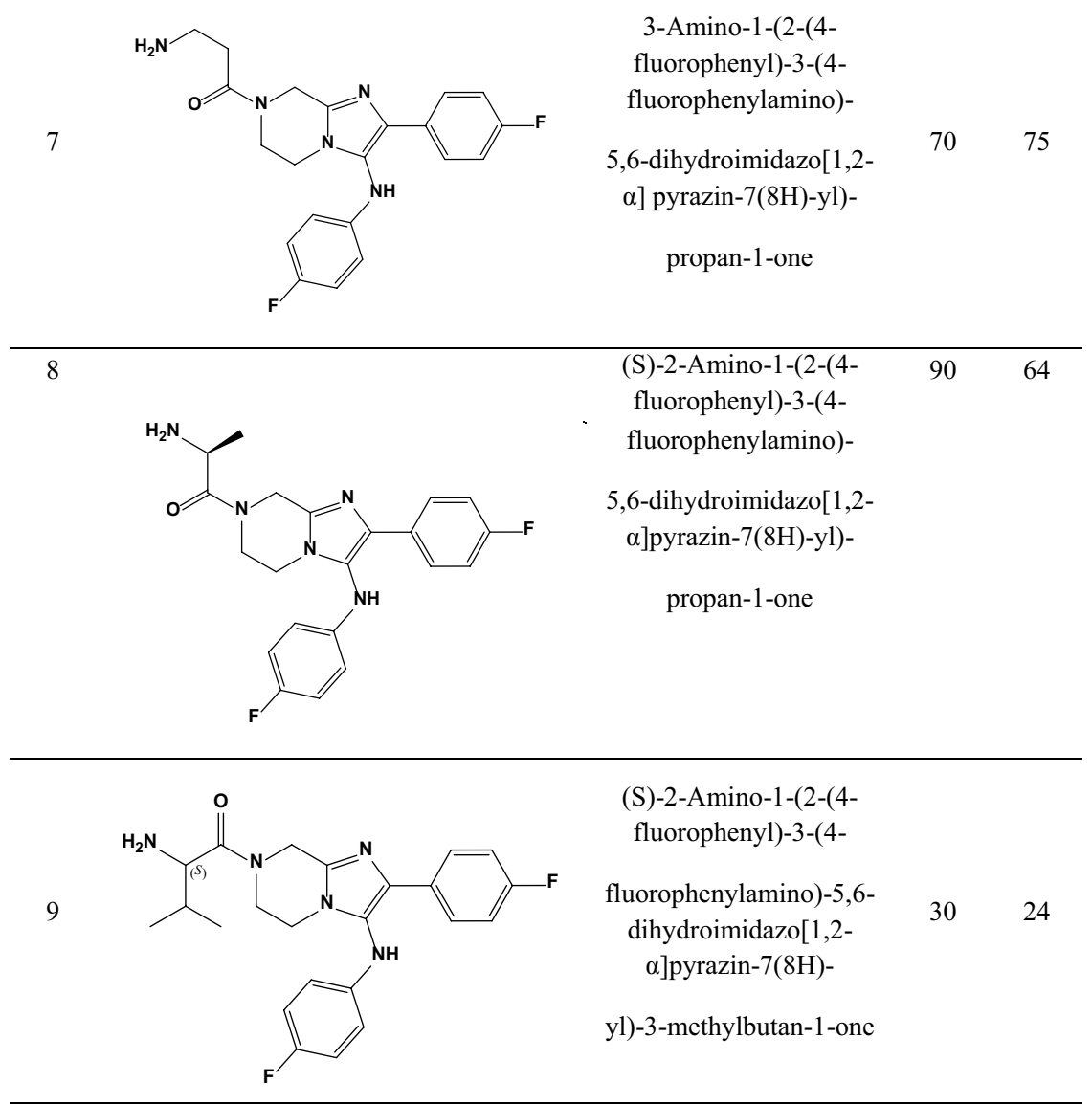


Table 1 (continued)

No.<smiles>NC(Cc1ccccc1)C(=O)N1CCn2c(nc(-c3ccc(F)cc3)c2Nc2ccc(F)cc2)C1</smiles>

(S)-2-Amino-1-(2-(4fluorophenyl)-3-(4-

fluorophenylamino)-5,6dihydroimidazo[1,2- $\alpha$ ] pyrazin- $7(8 \mathrm{H})$ -

yl)-3-phenylpropan-1-one

12<smiles>N[C@@H](Cc1ccccc1)C(=O)N1CCn2c(nc(-c3ccc(F)cc3)c2Nc2ccc(F)cc2)C1</smiles>

(R)-2-Amino-1-(2-(4fluorophenyl)-3-(4-

fluorophenylamino)-5,6dihydroimidazo[1,2- $\alpha$ ] pyrazin-7(8H)-

yl)-3-phenylpropan-1-one
13<smiles>CC(C)(N)C(=O)N1CCn2c(nc(-c3ccccc3)c2Nc2ccc(F)cc2)C1</smiles>

2-Amino-1-(3-((4fluorophenyl)amino)-2-

phenyl-5,6-

dihydroimidazo[1,2- $\alpha$ ] 200 methylpropan-

$$
\text { 1-one }
$$


Table 1 (continued)

No. Name and structure of the compounds $\begin{gathered}\begin{array}{c}\text { P. falciparum } \\ \text { strain } \mathrm{IC}_{50} \\ (\mathrm{nM})\end{array} \\ \begin{array}{c}\text { 2-Amino-1-(2-(4- } \\ \text { chlorophenyl)-3-((4- } \\ \text { fluorophenyl) }\end{array} \\ \begin{array}{c}\text { W2 } \\ \text { amino)-5,6- } \\ \text { dihydroimidazo[1,2- } \alpha] \\ \text { pyrazin-7(8H)-yl)- } \\ \text { ethanone }\end{array}\end{gathered}$<smiles>COc1ccc(-c2nc3n(c2Nc2ccc(F)cc2)CCN(C(=O)CN)C3)cc1</smiles>

2-Amino-1-(3-((4-

fluorophenyl)amino)-

2-(4-methoxyphenyl)5,6-dihydroimidazo[1,2-

$\alpha]$ pyrazin-7(8H)-

yl)ethanone

2-Amino-1-(3-((4-

fluorophenyl)amino)-2-

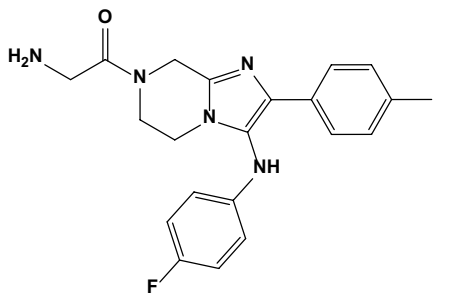

(p-tolyl)-

5,6-dihydroimidazo[1,2- $\quad 3140 \quad 3360$

$\alpha]$ pyrazin-7(8H)-

yl)ethanone

17

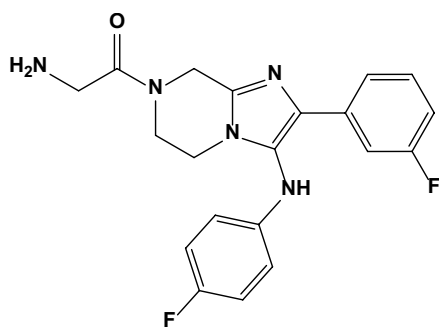

2-Amino-1-(3-((4-

fluorophenyl)amino)-2-

(3-fluorophenyl)-5,6dihydroimidazo[1,2- $\alpha$ ]

pyrazin-7(8H)-yl)-

$$
\text { ethanone }
$$

18<smiles>CC(C)(N)C(=O)N1CCn2c(nc(-c3ccccc3F)c2Nc2ccc(F)cc2)C1</smiles>

2-Amino-1-(2-(2-

fluorophenyl)-3-((4-

fluorophenyl)

amino)-5,6-

$1390 \quad 1284$

dihydroimidazo $[1,2-\alpha]$

pyrazin-7(8H)-yl)-

2-methylpropan-1-one 
Table 1 (continued)

No. Name and structure of the compounds $\begin{gathered}\begin{array}{c}\text { P. falciparum } \\ \text { strain } \mathrm{IC}_{50} \\ (\mathrm{nM})\end{array} \\ \begin{array}{c}\text { 2-Amino-1-(2-(3,4- } \\ \text { difluorophenyl)-3-(p- } \\ \text { tolylamino)- } \\ \text { 3,6-dihydroimidazo[1,2- } \\ \alpha] \text { pyrazin-7(8H)-yl)-2- } \\ \text { methylpropan-1-one }\end{array}\end{gathered}$

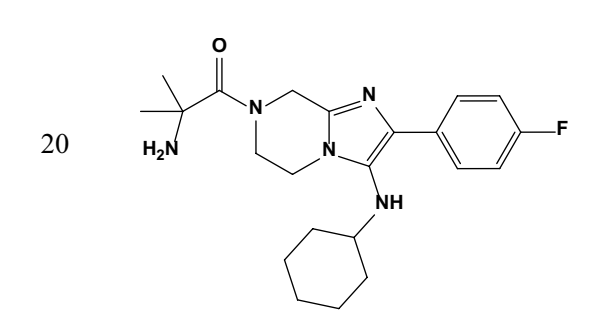

\section{2-Amino-1-(3-}

(cyclohexylamino)-2-(4-

fluorophenyl)-5,6dihydroimidazo[1,2- $\alpha$ ] pyrazin-7(8H)-yl)-2methylpropan-1-one

\section{2-Amino-1-(2-(4-}

fluorophenyl)-3-(pyridin-

3-ylamino)-5,6dihydroimidazo[1,2- $\alpha$ ] pyrazin-7(8H)-yl)-2-

21

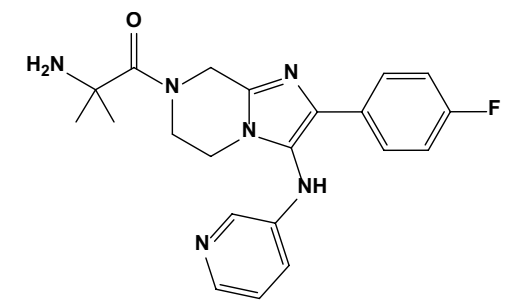
methylpropan-1-one

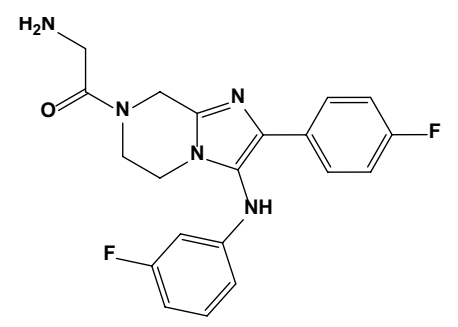

2-Amino-1-(2-(4-

fluorophenyl)-3-(3-

fluorophenylamino)-

5,6-dihydroimidazo[1,

a] pyrazin-7(8H)-yl)-

ethanone

23

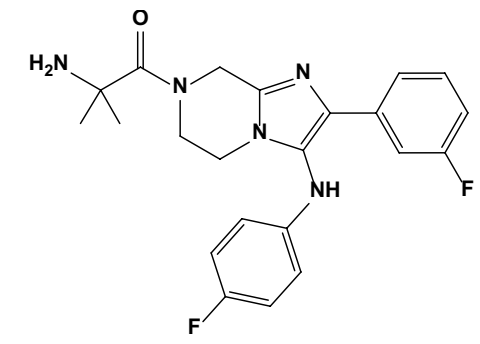

2-Amino-1-(2-(3-

fluorophenyl)-3-(4-

fluorophenylamino)-

5,6-dihydroimidazo[1,2-

50 71 $\alpha]$ pyrazin-7(8H)-yl)-2-

methylpropan-1-one 
Table 1 (continued)

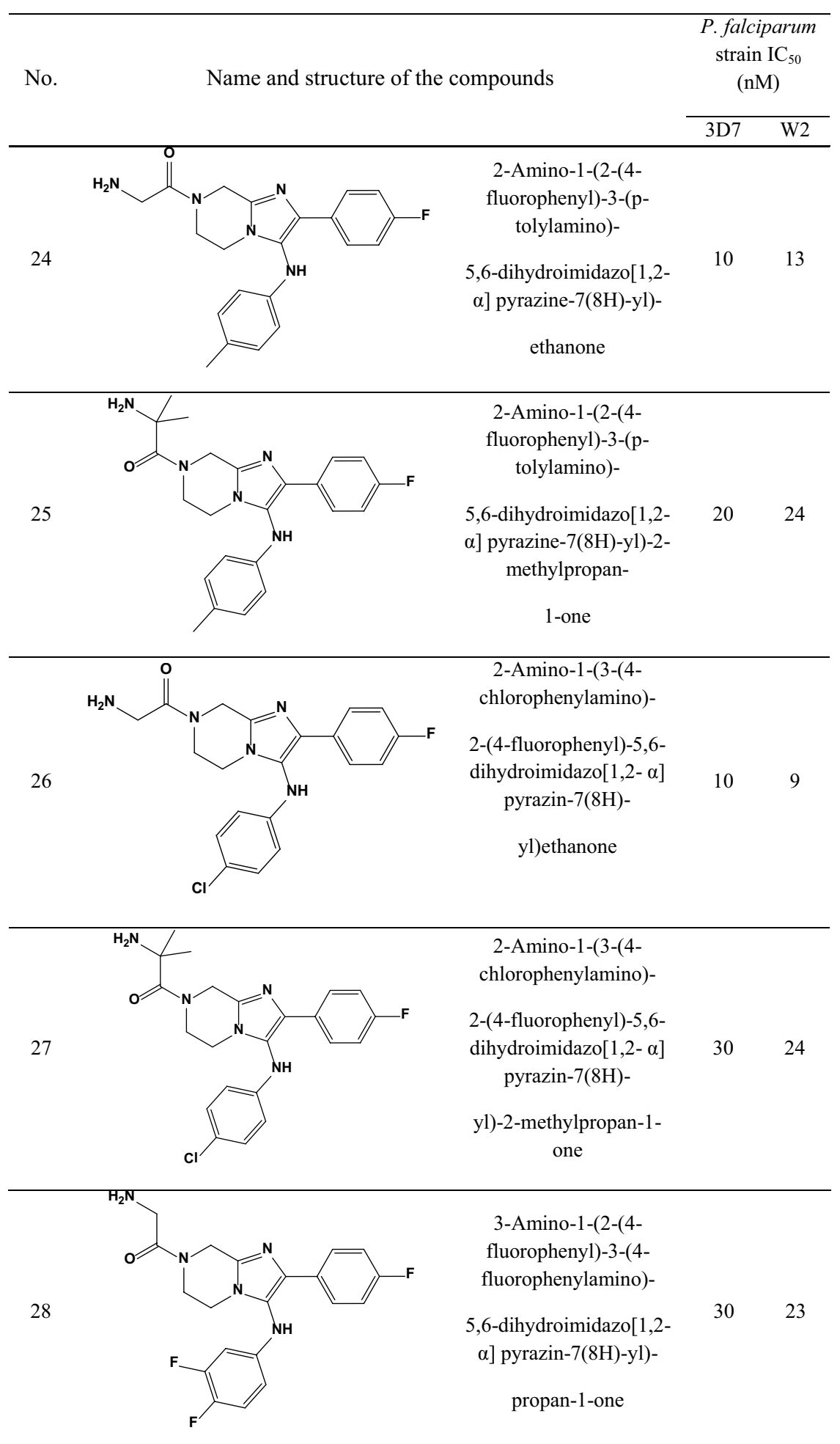


Table 1 (continued)

\begin{tabular}{lc}
\hline & $\begin{array}{c}\text { P. falciparum } \\
\text { strain } \mathrm{IC}_{50}\end{array}$ \\
No. Name and structure of the compounds & $(\mathrm{nM})$
\end{tabular}

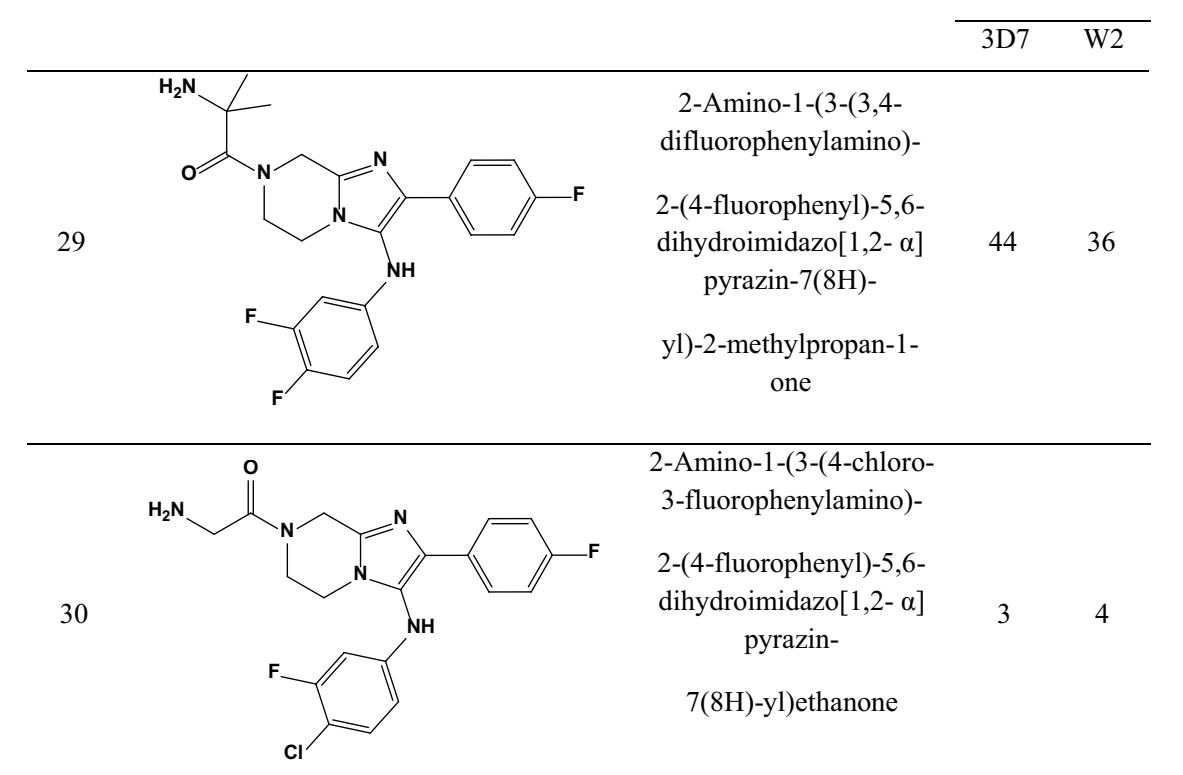

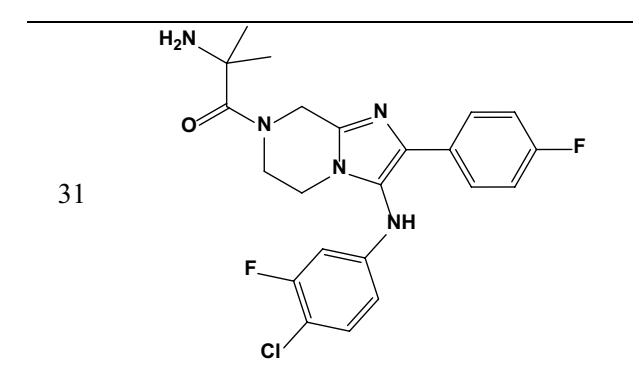
2-Amino-1-(3-(4-chloro-
3-fluorophenylamino)-
2-(4-fluorophenyl)-5,6- dihydro imidazo[1,2- $\alpha] \quad 40 \quad 52$ pyrazin-

7(8H)-yl)-2-

methylpropan-1-one

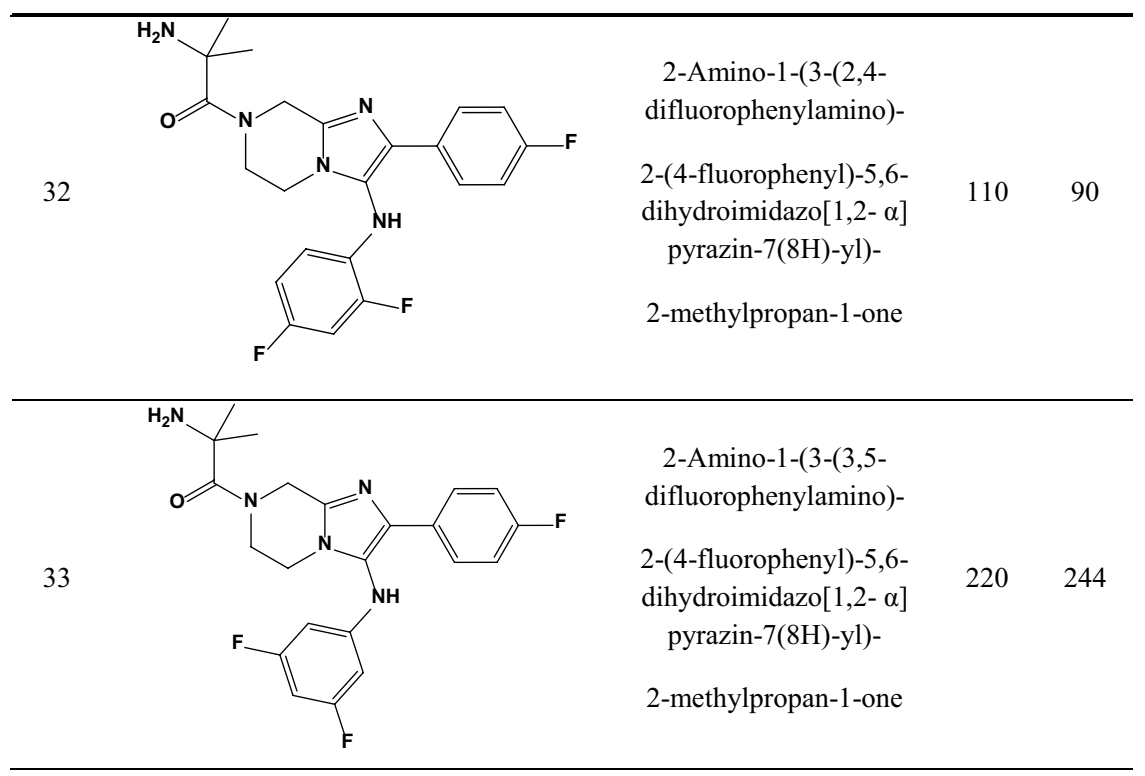


descriptors were removed. At the second step, for decreasing the redundancy existing in the descriptors, the correlation of descriptors with each other and with the biological activities $\left(\mathrm{pIC}_{50}\right)$ against $3 \mathrm{D} 7$ and W2 was examined and among the collinear ones $(r>0$. 95), the descriptors that had the highest correlation with $\mathrm{pIC}_{50}$ for 3D7 and W2 were retained. After these steps, the number of remaining descriptors for all the 33 compounds in each mode (against 3D7 and W2) was about 555 which were collected in an $\mathrm{n} \times \mathrm{m}$ data matrix (D), where $\mathrm{n}$ and $\mathrm{m}$ are the number of imidazolopiperazine derivatives $(=33)$ and the number of descriptors $(=555)$, respectively. The data set was randomly divided to training set with 23 compounds, test and validation set, each of them include 5 compounds.

It should be noted that the variable selection was done by stepwise multiple linear regression (SMLR) on the training set using SPSS (version 19.0, SPSS Inc., http:// www.spss.com). Artificial neural networks were done using MATLAB (version 7.6, Math work, Inc., http:// www.mathworks.com). All other statistical calculations and evaluations were also conducted in MATLAB. In ANN modeling, a two-layer feed-forward network with sigmoid hidden neurons and linear output neurons was used with only two hidden neurons. The mean square error was also used as the performance criteria of the network.

\section{Results}

In the first step, due to the preference of using the linear models to the non-linear ones [19], the QSAR modelling of the mentioned imidazolopiperazine derivatives with anti-malarial activities was investigated using the linear models. This effort did not have good results, by using multiple linear regression (MLR) and partial least square (PLS) models, and forced the authors to test the nonlinear models.

At the next step for evaluation the randomized distribution of the molecules belong to the three data set (the training, validation and test sets) in the space of descriptors, principal component analysis (PCA) was applied. The two-dimensional (2D) PCA plot (PC1 vs. PC2) of imidazolopiperazine derivative molecules for the data of two models (3D7 and W2) is displayed in Fig. 1.

\section{Variable selection}

Variable selection was done using SMLR on the $23 \times 555$ data matrix. The statistic parameters like Fisher's F value (F) and correlation coefficient $\left(\mathrm{R}^{2}\right)$ were employed for evaluation the goodness of the selected variables and as fitting criteria. In this way, variables with the most significant values of $\mathrm{F}$ and highest correlation coefficient were selected by inserting into/removing from the model respectively and 12 variables were selected by using this approach. In the next step, the models with 1 to 12 variables were checked using ANN method for training and validation sets [20] and it was found that in the models with more than 6 variables despite of improvement in the training set results, the prediction ability of the validation set reduced because of overfitting [21]. The results of SMLR for the selected variables are summarized in Additional file 1: Tables S1-S3 for the 3D7 model and in Additional file 1: Table S4-S6 for the W2 model.

So the number of 6 variables was selected for both 3D7 and W2 models. The 6 selected descriptors for modelling the biological activities $\left(\mathrm{pIC}_{50}\right)$ against 3D7 and W2 are represented in Additional file 1: Tables S7,

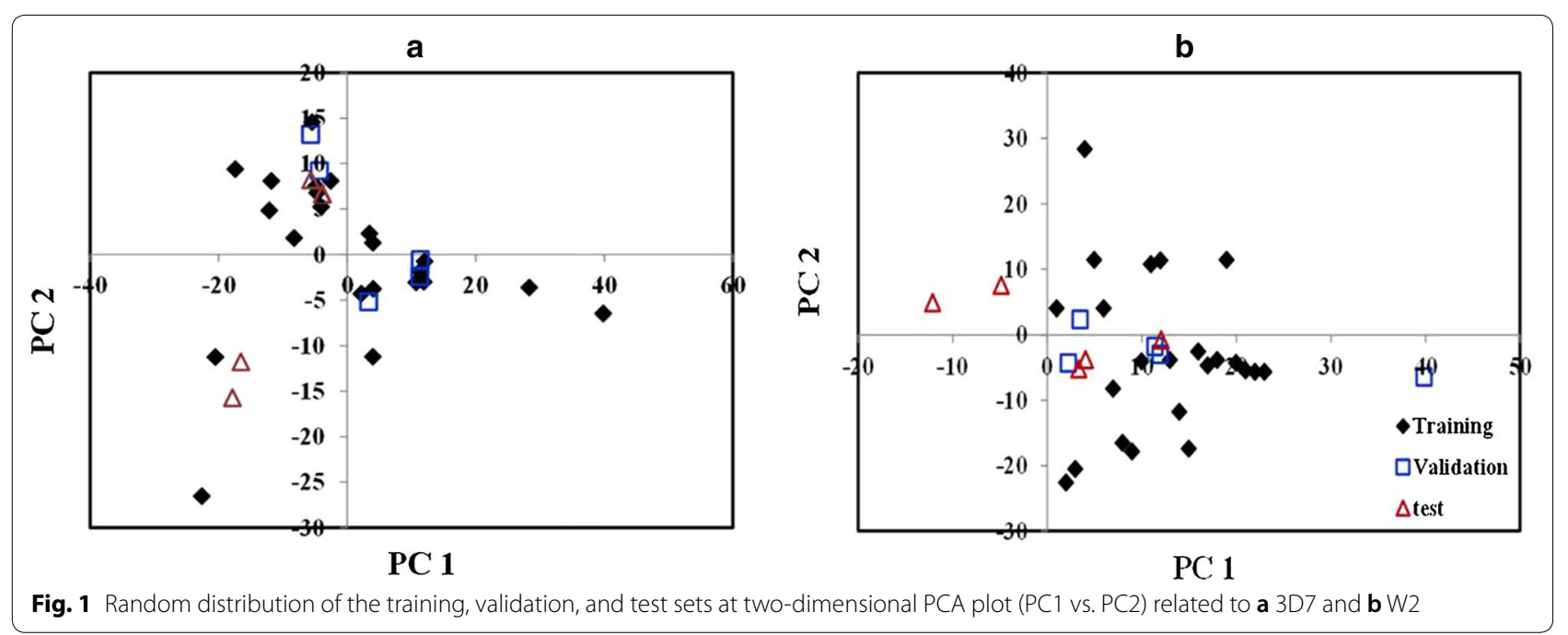


Table 2 The definition of the used molecular descriptors for modelling of two kinds of activities (3D7 and W2)

\begin{tabular}{|c|c|c|c|}
\hline $\begin{array}{l}\text { Molecular } \\
\text { descriptors }\end{array}$ & Definition & Descriptor category & Strain \\
\hline GATS4m & Geary autocorrelation of lag 4 weighted by mass & 2D autocorrelations & 3D7 \\
\hline GATS7m & Geary autocorrelation of lag 7 weighted by mass & 2D autocorrelations & 3D7 \\
\hline Mor06u & Signal 06/unweighted & 3D-MoRSE descriptors & 3D7 \\
\hline Mor31u & 3D-MoRSE, signal 31/unweighted & 3D-MoRSE descriptors & $3 \mathrm{D} 7$ \\
\hline$+\mathrm{R} 3 \mathrm{e}$ & R maximal autocorrelation of lag 3/weighted by Sanderson electronegativity & GETAWAY descriptors & $3 \mathrm{D} 7$ \\
\hline$+R 2 p$ & R maximal autocorrelation of lag $2 /$ weighted by polarizability & GETAWAY descriptors & $3 \mathrm{D} 7$ \\
\hline BEHm3 & Highest eigenvalue n.3 of Burden matrix/weighted by atomic masses & Burden eigenvalues & W2 \\
\hline MATS7m & Moran autocorrelation of lag 7 weighted by mass & 2D autocorrelations & W2 \\
\hline RDF020m & Radial distribution function-020/weighted by mass & RDF descriptors & W2 \\
\hline Mor23u & 3D-MoRSE signal 23/unweighted & 3D-MoRSE descriptors & W2 \\
\hline Mor20p & 3D-Morse signal 23/weighted by polarizability & 3D-MoRSE descriptors & W2 \\
\hline MLOGP & Moriguchi octanol-water partition coefficient & Molecular properties & W2 \\
\hline
\end{tabular}

Table 3 The pair correlation coefficient $\left(R^{2}\right)$ and the variance inflation factor (VIF) for the 6 descriptors at the training and total set for 3D7 model

\begin{tabular}{|c|c|c|c|c|c|c|c|}
\hline & GATS7m & Mor31u & Mor06u & $\mathrm{R} 2 \mathrm{p}+$ & GATS4m & $\mathrm{R} 3 \mathrm{e}+$ & VIF \\
\hline \multicolumn{8}{|l|}{ GATS7 } \\
\hline Trainng set & 1.00 & & & & & & 2.21 \\
\hline Total set ${ }^{a}$ & 1.00 & & & & & & 2.85 \\
\hline \multicolumn{8}{|l|}{ Mor31u } \\
\hline Trainng set & 0.38 & 1.00 & & & & & 2.86 \\
\hline Total set ${ }^{a}$ & 0.37 & 1.00 & & & & & 1.43 \\
\hline \multicolumn{8}{|l|}{ Mor06u } \\
\hline Trainng set & 0.00 & 0.15 & 1.00 & & & & 1.44 \\
\hline Total set ${ }^{a}$ & 0.01 & 0.12 & 1.00 & & & & 1.44 \\
\hline \multicolumn{8}{|l|}{$R 2 p+$} \\
\hline Trainng set & 0.1 & 0.25 & 0.11 & 1.00 & & & 1.47 \\
\hline Total set ${ }^{\mathrm{a}}$ & 0.08 & 0.21 & 0.12 & 1.00 & & & 1.46 \\
\hline \multicolumn{8}{|l|}{ GATS4m } \\
\hline Trainng set & 0.03 & 0.19 & 0.12 & 0.18 & 1.00 & & 1.49 \\
\hline Total set ${ }^{a}$ & 0.05 & 0.26 & 0.10 & 0.19 & 1.00 & & 2.57 \\
\hline \multicolumn{8}{|l|}{ R3e+ } \\
\hline Trainng set & 0.03 & 0.06 & 0.00 & 0.01 & 0.10 & 1.00 & 1.44 \\
\hline Total set ${ }^{a}$ & 0.11 & 0.02 & 0.04 & 0.01 & 0.06 & 1.00 & 1.52 \\
\hline
\end{tabular}

a Total set: total of training, validation and test sets

S8, respectively. It should be mentioned that the results of test set were not considered during selection of the optimum model. The definition of the used molecular descriptors for modelling the biological activities $\left(\mathrm{pIC}_{50}\right)$ for the 3D7 and W2 strain are presented in Table 2.

After the selection of the descriptors, the evaluation of correlation was done using the pair-correlation matrix for 23 training compounds and the total of training and test sets (28 compounds). The related data are shown in Tables 3 and 4 for six descriptors of the 3D7 and W2 models respectively.

\section{Model development}

At the model development and validation steps, the training set with 23 compounds (70\% of the imidazolopiperazine derivative molecules) was used for artificial neural networks modelling. Feed forward artificial neural networks with Levenberg-Marquardt algorithm were used for this purpose. The validation and test sets (each of them with 5 compounds containing $15 \%$ of the imidazolopiperazine derivative molecules) were used to validate the prediction ability of the proposed anti-malarial 
Table 4 The pair correlation coefficient $\left(R^{2}\right)$ and the variance inflation factor (VIF) for the 6 descriptors at the training and total set for W2 model

\begin{tabular}{|c|c|c|c|c|c|c|c|}
\hline & Mor20p & MATS7m & RDF020m & MLOGP & BEHm3 & Mor23u & VIF \\
\hline \multicolumn{8}{|l|}{ Mor20p } \\
\hline Training set & 1.00 & & & & & & 1.63 \\
\hline Total set ${ }^{a}$ & 1.00 & & & & & & 2.67 \\
\hline \multicolumn{8}{|l|}{ MATS7m } \\
\hline Training set & 0.00 & 1.00 & & & & & 1.62 \\
\hline Total set ${ }^{\mathrm{a}}$ & 0.00 & 1.00 & & & & & 1.64 \\
\hline \multicolumn{8}{|l|}{ RDF020m } \\
\hline Training & 0.02 & 0.01 & 1.00 & & & & 1.56 \\
\hline Total set ${ }^{a}$ & 0.011 & 0.00 & 1.00 & & & & 1.41 \\
\hline \multicolumn{8}{|l|}{ MLOGP } \\
\hline Training set & 0.15 & 0.18 & 0.07 & 1.00 & & & 1.91 \\
\hline Total set ${ }^{a}$ & 0.04 & 0.20 & 0.01 & 1.00 & & & 1.55 \\
\hline \multicolumn{8}{|l|}{ BEHm3 } \\
\hline Training set & 0.01 & 0.08 & 0.19 & 0.00 & 1.00 & & 1.34 \\
\hline Total set ${ }^{a}$ & 0.38 & 0.00 & 0.01 & 0.14 & 1.00 & & 2.24 \\
\hline \multicolumn{8}{|l|}{ Mor23u } \\
\hline Training set & 0.14 & 0.13 & 0.00 & 0.00 & 0.01 & 1.00 & 1.38 \\
\hline Total set ${ }^{\mathrm{a}}$ & 0.39 & 0.19 & 0.07 & 0.00 & 0.15 & 1.00 & 2.21 \\
\hline
\end{tabular}

a Total set: total of training, validation and test sets

Table 5 Statistical parameters of the artificial neural networks models used for prediction of anti-malarial activity at 3D7 and W2

\begin{tabular}{|c|c|c|c|c|c|c|c|}
\hline & Number of compounds & $3 \mathrm{D} 7^{\mathrm{a}, \mathrm{b}}$ & & & $W 2^{c, d}$ & & \\
\hline & & $\mathbf{R}$ & $R^{2}$ & MSE & $\mathbf{R}$ & $\mathrm{R}^{2}$ & MSE \\
\hline Training set & 23 & 0.973 & 0.947 & 0.036 & 0.964 & 0.929 & 0.030 \\
\hline Validation set & 5 & 0.979 & 0.959 & 0.051 & 0.892 & 0.797 & 0.290 \\
\hline Test set & 5 & 0.959 & 0.920 & 0.254 & 0.901 & 0.813 & 0.740 \\
\hline
\end{tabular}

a Average absolute deviation (AAD) for 3D7 model $=0.168$

b Percentage average absolute relative error (AARE\%) for 3D7 model $=2.98 \%$

c Average absolute deviation (AAD) for W2 model $=0.257$

d Percentage average absolute relative error (AARE\%) for W2 model $=4.20 \%$

models. The statistical parameters of the used ANN models is represented in Table 5.

The actual and predicted amounts of $\mathrm{pIC}_{50}$ of the used imidazolopiperazine derivatives as anti-malarial structures against 3D7 and W2 strain are represented in Table 6. There is good agreement between predicted and actual values of $\mathrm{pIC}_{50}$ in the proposed anti-malarial model for 3D7 activity and can be seen visually in Fig. 2 . About model constructed for activity against W2 however the training and validation was acceptable but the prediction ability in the external test set was not as good as 3D7.

Despite the good agreement between actual and predicted values in the two 3D7 and W2 models and specifically in the first one, but because the high number of descriptors (about 555 descriptors) which were selected in the variable selection step, there was the possibility of obtaining chancy models [22]. For evaluation of chance correlation, $y$-scrambling test was done. The dependent variable of the two 3D7 and W2 models (the experimental $\mathrm{pIC}_{50}$ of the selected derivatives) was randomly shuffled 30 times and ANN was run on them each time. The maximum correlation coefficient of the test set $\left(\mathrm{R}_{M P}^{2}\right)$ for these scrambled 3D7 and W2 models were 0.09 and 0.13 respectively. These low values of the correlation coefficients of the scrambled models $\left(\mathrm{R}_{\mathrm{MP}}^{2}\right)$ in comparison to the original 3D7 and W2 models imply the absence of chance correlation. 
Table 6 Experimental and predicted activities $\left(\mathrm{plC}_{50}\right.$ ) of the imidazolopiperazine derivatives as anti-malarial structures against 3D7 and W2

\begin{tabular}{|c|c|c|c|c|c|c|c|}
\hline \multirow[t]{2}{*}{ Compound number } & \multicolumn{3}{|l|}{ 3D7 } & \multirow[t]{2}{*}{ Compound number } & \multicolumn{3}{|l|}{ W2 } \\
\hline & $\begin{array}{l}\mathrm{plC}_{50} \\
\text { (exp) }\end{array}$ & $\begin{array}{l}\mathrm{plC}_{50} \\
\text { (pred) }\end{array}$ & Residual & & $\begin{array}{l}\mathrm{plC}_{50} \\
\text { (exp) }\end{array}$ & $\begin{array}{l}\mathrm{plC}_{50} \\
\text { (pred) }\end{array}$ & Residual \\
\hline 1 & 6.201 & 6.309 & -0.108 & 1 & 6.013 & 5.959 & 0.054 \\
\hline 2 & 5.629 & 6.269 & -0.640 & 2 & 5.567 & 5.527 & 0.040 \\
\hline 3 & 5.936 & 5.990 & -0.054 & 3 & 5.924 & 5.890 & 0.034 \\
\hline 4 & 7 & 6.996 & 0.004 & $4^{\mathrm{a}}$ & 4.258 & 3.901 & 0.357 \\
\hline 5 & 5.699 & 5.711 & -0.012 & 5 & 5.757 & 5.620 & 0.137 \\
\hline 6 & 6.699 & 6.695 & 0.004 & 6 & 6.638 & 6.624 & 0.014 \\
\hline 7 & 6.155 & 6.269 & -0.114 & $7^{\mathrm{a}}$ & 6.125 & 6.629 & -0.504 \\
\hline 8 & 6.046 & 6.035 & 0.011 & 8 & 6.194 & 6.413 & -0.219 \\
\hline 9 & 6.523 & 6.269 & 0.254 & 9 & 6.62 & 6.519 & 0.101 \\
\hline 10 & 6.699 & 6.269 & 0.430 & $10^{\mathrm{b}}$ & 6.602 & 6.389 & 0.213 \\
\hline $11^{\mathrm{b}}$ & 5.959 & 6.269 & -0.310 & 11 & 5.917 & 5.885 & 0.032 \\
\hline $12^{b}$ & 6.155 & 6.269 & -0.114 & 12 & 6.229 & 6.164 & 0.065 \\
\hline 13 & 5.699 & 5.677 & 0.022 & 13 & 5.775 & 5.709 & 0.066 \\
\hline 14 & 5.18 & 5.192 & -0.012 & 14 & 5.36 & 5.369 & -0.009 \\
\hline $15^{\mathrm{a}}$ & 4.644 & 4.252 & 0.392 & $15^{\mathrm{b}}$ & 4.769 & 4.600 & 0.169 \\
\hline 16 & 4.503 & 4.252 & 0.251 & $16^{b}$ & 4.474 & 3.809 & 0.665 \\
\hline $17^{\mathrm{a}}$ & 7 & 6.965 & 0.035 & 17 & 6.523 & 6.550 & -0.027 \\
\hline $18^{b}$ & 4.857 & 4.387 & 0.470 & 18 & 4.891 & 4.946 & -0.055 \\
\hline 19 & 6.222 & 6.296 & -0.074 & 19 & 6.301 & 5.910 & 0.391 \\
\hline 20 & 4.017 & 4.252 & -0.235 & 20 & 4.223 & 4.251 & -0.028 \\
\hline 21 & 4.85 & 4.858 & -0.008 & 21 & 4.479 & 4.451 & 0.028 \\
\hline 22 & 6.301 & 6.270 & 0.031 & $22^{\mathrm{a}}$ & 6.469 & 6.369 & 0.100 \\
\hline 23 & 6.301 & 6.269 & 0.032 & 23 & 6.149 & 6.091 & 0.058 \\
\hline 24 & 7 & 6.971 & 0.029 & $24^{\mathrm{a}}$ & 6.886 & 5.950 & 0.936 \\
\hline 25 & 6.699 & 6.698 & 0.001 & $25^{\mathrm{b}}$ & 6.62 & 5.130 & 1.490 \\
\hline 26 & 7 & 6.987 & 0.013 & $26^{a}$ & 7.046 & 6.614 & 0.432 \\
\hline $27^{b}$ & 6.523 & 7.278 & -0.755 & 27 & 6.62 & 6.485 & 0.135 \\
\hline $28^{\mathrm{a}}$ & 6.523 & 6.528 & -0.005 & 28 & 6.638 & 6.357 & 0.281 \\
\hline $29^{\mathrm{a}}$ & 6.357 & 6.269 & 0.088 & 29 & 6.444 & 6.240 & 0.204 \\
\hline 30 & 7.523 & 7.526 & -0.003 & $30^{\mathrm{b}}$ & 7.398 & 6.414 & 0.984 \\
\hline 31 & 6.398 & 6.269 & 0.129 & 31 & 6.284 & 6.251 & 0.033 \\
\hline $32^{\mathrm{a}}$ & 5.959 & 6.268 & -0.309 & 32 & 6.046 & 6.095 & -0.049 \\
\hline $33^{b}$ & 5.658 & 6.269 & -0.611 & 33 & 5.613 & 6.176 & -0.563 \\
\hline
\end{tabular}

a The selected molecules as the validation data set

${ }^{b}$ The selected molecules as the test data set

\section{Applicability domain}

Applicability domain (AD) of a QSAR model is an important point, because it defines the model limitations. Actually "the applicability domain of a (Q)SAR model is the response and chemical structure space in which the model makes predictions with a given reliability" [23].

Different methods have been suggested for calculation of $\mathrm{AD}$ [24]. One of the recommended approaches to define $\mathrm{AD}$ is the method based on leverage and standard residual. The Williams plot that displays the standardized residuals versus leverage (hat diagonal) values is a way to verify the AD of a QSAR model $[25,26]$. Leverage is proportional to the Mahalanobis distance of a query chemical from the centroid of the training set. For a given descriptor dataset $\mathbf{X}$, the leverages are calculated with the $\left(\mathrm{H}=\mathrm{X}\left(\mathrm{X}^{\prime} \mathrm{X}\right)^{-1} \mathrm{X}\right)$ equation, where $\mathrm{X}^{\prime}$ is the transpose of $\mathrm{X}$ matrix $[24,27]$. The diagonal value $\left(h_{i}\right)$ represents the leverage value for $i$ th point in the $\mathrm{X}$ dataset from the centre of the set of $\mathrm{X}$ observations. The higher leverage values represent the far compounds from the centre 

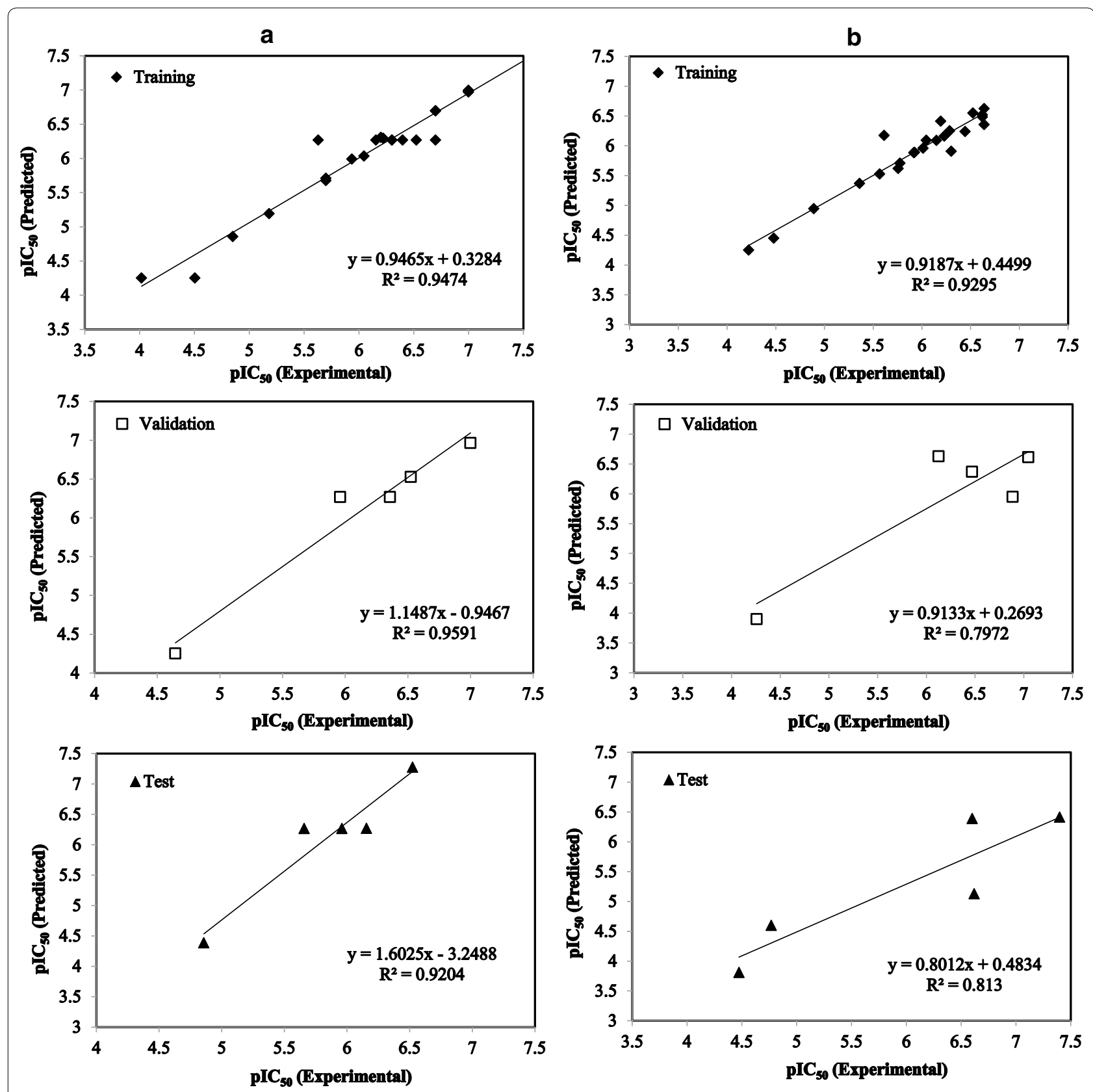

Fig. 2 Plot of the $\mathrm{plC}_{50}$ predicted (using artificial neural networks model) versus the experimental $\mathrm{plC}_{50}$ for $\mathbf{a} 3 \mathrm{D} 7$ and $\mathbf{b}$ W2

and they are more influential in model building [24]. It should be mentioned that a warning value for leverage is defined; so that if a query chemical has higher leverage than the warning value, it can be as unreliable prediction [24]. This warning leverage generally is equal to $3 p / n$ where $p$ is the number of model descriptors plus one (here $p=7$ ), and $n$ is the number of compounds used for the training model $[24,28]$. It should be noted if the leverage of a query chemical was less than the warning value, there is not necessarily to be stayed on the range of the applicability domain of the model, and may be it has high standardized residuals. So in the Williams plot both of the two parameters (leverage values and standardized residuals) for surveying the AD of model has been considered. The Williams plots of 33 compounds of the models with 6 descriptors for 3D7 and W2 are displayed in Fig. 3. 

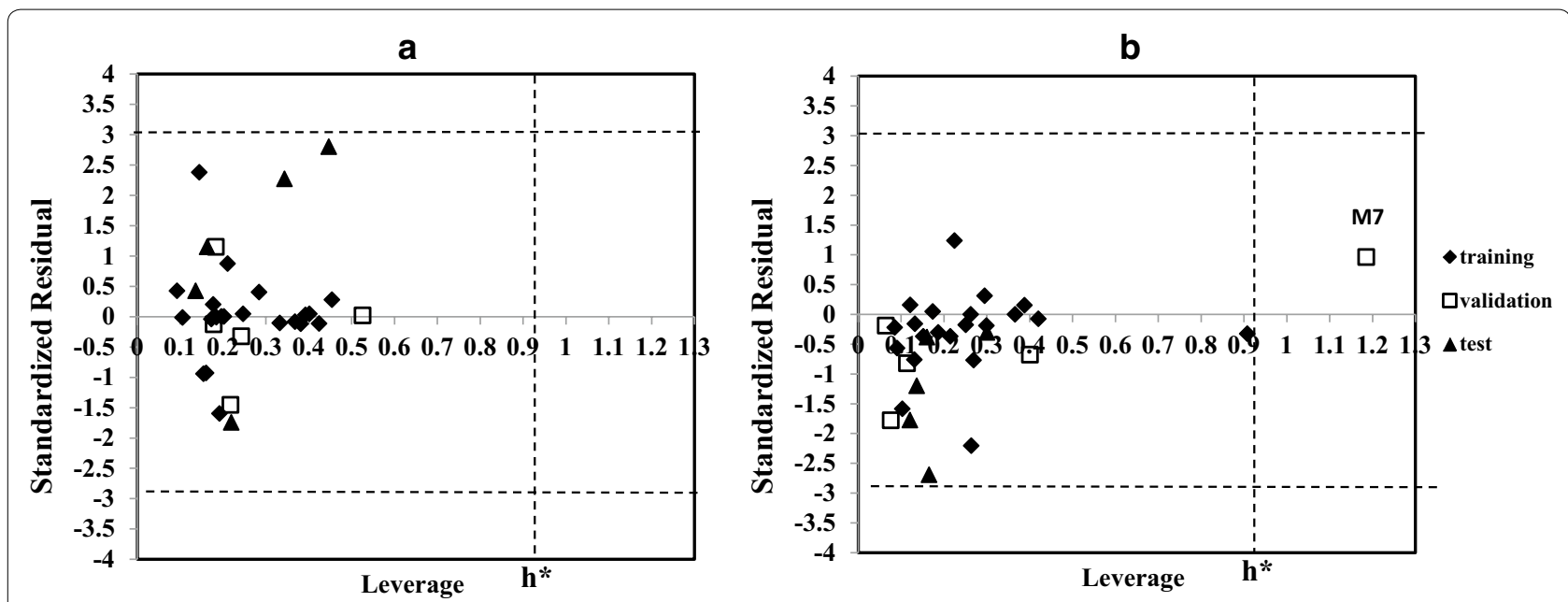

Fig. 3 The Williams plots of the 33 compounds obtained by 6 descriptors used in artificial neural network models for a 3D7 and b W2

\section{Discussion}

In this research an artificial neural network was employed to gain a set of descriptors and to build a QSAR model for antimalarial activity. The controversial topic is how each step for QSAR model building such as data collection, model validation and prediction is performed.

The randomized selection of prediction and test subsets is a good method for external evaluation of the final model [29]. For each 3D7 and W2 model, As seen in Fig. 1, the two-dimensional PCA plot (PC1 vs. PC2) show that the molecules belongs to the three training, validation and test data sets are randomly distributed in the space of descriptors.

The other important step in any QSAR study is variable selection, because the method which is used for descriptor choosing has a great impact on all subsequent steps in drug design. The ideal path for variable selection is extensively search to all possible combinations of the initial descriptors, which is impossible except with small data set which have small number of descriptors [30].

For this purpose after using stepwise MLR (SMLR), the variables with the most significant Fisher's value (F) and with the highest correlation coefficient $\left(R^{2}\right)$ were selected. In this way variables with the most significant Fisher's value and the highest correlation coefficient were selected by inserting into/removing from the model. The number of 12 variables were checked using ANN method for training and validation sets. At the end it was found that the prediction ability of the models with 6 variables (reported in Table 2) are the best.

The next step was the evaluation of correlation in the selected descriptors. In the case of correlation between descriptors, the efficiency of the QSAR models are reduced and leads to biased estimation [31]. The pair correlation matrix was evaluated for the six descriptors of the two 3D7 and W2 models (Tables 3 and 4).It is clear from the Tables 3 and 4, no serious dependency is found in both descriptor set.

In addition to pair correlation, another kind of linear dependency can limit the accuracy of model which is known as multicollinearity which is shown the linear dependency of a variable (predictor) to all others [31]. Variance inflation factor (VIF), which is given in the following equation, is a popular diagnostic index for appearing multicollinearity [32].

$$
\mathrm{VIF}_{\mathrm{i}}=\frac{1}{1-R_{i}^{2}}
$$

where $R_{i}^{2}$ is the $R^{2}$-value obtained by regressing the $i$ th predictor on the other predictors [32].

As it is shown in the last column of Tables 3 and 4, all the calculated VIF are less than 3 , and as regards to the proposed critical value for VIF that is equal to 5.0, the information of none of the six used descriptors for both 3D7 and W2 models has multicollinearity with the other descriptors and the resulting models are acceptable.

Looking at the results of model development and validation (Table 5), we find that the values of $R^{2}$ and MSE of the training set for both of 3D7 and W2 models are good and express the good fitness of the models. Nevertheless it is necessary to use validation and test set to check the prediction ability of the anti-malarial models. As can be seen in Table 5, the statistics of validation and test sets of the model suggested for inhibitory against 3D7 strain were excellent $\left(R_{\text {val }}^{2}=0.959\right.$, $\left.\mathrm{R}_{\text {test }}^{2}=0.920\right)$ and the values of MSE for the two validation and test data sets were also good (0.051 and 0.254 , respectively). The model generated for inhibitory against W2 strain with $R_{\text {val }}^{2}=0.797$ and $R_{\text {test }}^{2}=0.813$ was acceptable and the MSE values of its validation and 
test data sets $(0.290$ and 0.740 , respectively) were not good in case of test set. It is clear from the results that the anti-3D7 activity model with the excellent statistics values for training, validation, and test $\left(R_{\text {train }}^{2}=0.947\right.$, $\left.\mathrm{R}_{\text {val }}^{2}=0.959, \mathrm{R}_{\text {test }}^{2}=0.920\right)$ was better from the antiW2 activity model and the latter was not very good but has acceptable performance which can be used for a brief estimation of activity against W2.

Also from the Williams plots (Fig. 3), it is clear that all the 33 compounds, except molecule No. 7 in W2 model have leverage values lower than the warning leverage. Also all the compounds were in the acceptable range of standardized residual $( \pm 3 \sigma)$. These results confirm that the prediction using six descriptors (which were selected by SMLR) in ANN models can be acceptable.

Also from the Williams plots (Fig. 3), it is clear that all the 33 compounds, except molecule No. 7 in W2 model have leverage values lower than the warning leverage. Also all the compounds were in the acceptable range of standardized residual $( \pm 3 \sigma)$. These results confirm that the prediction using six descriptors (which were selected by SMLR) in ANN models can be acceptable.

\section{Conclusion}

Malaria is a deadly infectious disease, which is prevalent especially in the tropical developing countries. Resistance to existing anti-malarial drugs is a factor forcing researchers to develop or modify the anti-malarial compounds. The QSAR study with highlighting the structure activity relationships which correlate the compounds' structural features with the observed anti-malarial activities could be a suitable way to design and to modify anti-malarial compounds. Actually in silico drug design methods, such as QSAR, play an important role in the drug design process due to saving money and time.

In this research, the anti-malarial activity of 33 imidazolopiperazine derivatives was investigated at 3D7 and W2 strain, using QSAR method. The linear methods, such as MLR and PLS models was not suitable but nonlinear ANN showed good performance. The statistical parameters were used to evaluate the results. The results of $\mathrm{R}^{2}$, MSE and leverage value showed that the prediction ability of ANN method for estimation of the anti-malarial activity in imidazolopiperazine compounds is good and can be used as a virtual tool for synthesis of analogous compounds.

\section{Supplementary information}

Supplementary information accompanies this paper at https://doi. org/10.1186/s12936-019-2941-5.

Additional file 1.Additional tables.

\section{Abbreviations}

AD: applicability domain; ANN: artificial neural network; MLR: multiple linear regression; MSE: mean square error; PC: principal component; PCA: principal component analysis; PLS: partial least square; QSAR: quantitative structure activity relationship; SMLR: stepwise multiple linear regression; VIF: variance inflation factor.

\section{Acknowledgements}

Support of Shiraz University of Medical Sciences (98-01-42-20527) is gratefully acknowledged.

\section{Research involving human participants and/or animals}

This article does not contain any studies with human participants or animals performed by any of the authors.

\section{Authors' contributions}

SY was the supervisor of team in all research steps including data gathering, data analysis, and manuscript preparation/revision. RE had contribution in the data analysis and preparation of results and revision of this manuscript. MM had contributed to the development of this analysis and the writing and revising of this manuscript. All authors read and approved the final manuscript.

\section{Availability of data and materials}

All the information about datasets during and/or analysed during the current research are included in the manuscript, additional file and other required data is available from the corresponding author on reasonable request.

\section{Ethics approval and consent to participate}

This article does not contain any studies involving human participants or clinical trial to require their consent for publication. Thus no ethical limitation was involved. The references of all data used in this research were also noted in the manuscript completely.

\section{Competing interests}

The authors declare that they have no competing interests.

\section{Author details}

${ }^{1}$ Research Center for Health Sciences, Institute of Health, Department of Occupational Health Engineering, School of Health, Shiraz University of Medical Sciences, Shiraz, Iran. ${ }^{2}$ Medicinal and Natural Products Chemistry Research Center, Shiraz University of Medical Sciences, Shiraz, Iran. ${ }^{3}$ Department of Chemistry, Shiraz Branch, Islamic Azad University, Shiraz, Iran.

Received: 30 May 2019 Accepted: 27 August 2019

Published online: 14 September 2019

\section{References}

1. Mishra M, Mishra VK, Kashaw V, Iyer AK, Kashaw SK. Comprehensive review on various strategies for antimalarial drug discovery. Eur J Med Chem. 2017;125:1300-20.

2. Biamonte MA, Wanner J, Le Roch KG. Recent advances in malaria drug discovery. Bioorg Med Chem Lett. 2013;23:2829-43.

3. Marson BM, Vilhena R de O, Fachi MM, Pontes FLD, de Almeida BMM, Pontarolo R. Challenges and perspectives in malaria treatment. In: Malaria. Avid Science Publ; 2019. http://www.avidscience.com/book/malaria/.

4. Flannery EL, Chatterjee AK, Winzeler EA. Antimalarial drug discoveryapproaches and progress towards new medicines. Nat Rev Microbiol. 2013;11:849-62.

5. Calderón F, Wilson DM, Gamo F-J. Antimalarial drug discovery: recent progress and future directions. Prog Med Chem. 2013;52:97-151.

6. Ekins S, Mestres J, Testa B. In silico pharmacology for drug discovery: applications to targets and beyond. Br J Pharmacol. 2007;152:21-37.

7. Kumar Ojha P, Roy K. The current status of antimalarial drug research with special reference to application of QSAR models. Comb Chem High Throughput Screen. 2015;18:91-128.

8. Agrawal VK, Srivastava R, Khadikar PV. QSAR Studies on some antimalarial sulfonamides. Bioorg Med Chem. 2001;9:3287-93. 
9. Cheng F, Shen J, Luo X, Zhu W, Gu J, Ji R, et al. Molecular docking and 3-D-QSAR studies on the possible antimalarial mechanism of artemisinin analogues. Bioorg Med Chem. 2002;10:2883-91.

10. Katritzky AR, Kulshyn OV, Stoyanova-Slavova I, Dobchev DA, Kuanar M, Fara DC, et al. Antimalarial activity: a QSAR modeling using CODESSA PRO software. Bioorg Med Chem. 2006;14:2333-57.

11. Cardoso FJB, de Figueiredo AF, da Silva Lobato M, de Miranda RM, de Almeida RCO, Pinheiro JC. A study on antimalarial artemisinin derivatives using MEP maps and multivariate QSAR. J Mol Model. 2008;14:39-48.

12. Cheoymang A, Na-Bangchang K. A systematic review: application of in silico models for antimalarial drug discovery. Afr J Pharm Pharmacol. 2018;12:159-67.

13. Leong FJ, Zhao R, Zeng S, Magnusson B, Diagana TT, Pertel P. A firstin-human randomized, double-blind, placebo-controlled, single- and multiple-ascending oral dose study of novel imidazolopiperazine KAF156 to assess its safety, tolerability, and pharmacokinetics in healthy adult volunteers. Antimicrob Agents Chemother. 2014;58:6437-43.

14. Chia PY, Hsu LY, Yeo TW. Malaria in 2018: looking to the past and moving into the future. Ann Acad Med. 2018;47:4.

15. Nagle A, Wu T, Kuhen K, Gagaring K, Borboa R, Francek C, et al. Imidazolopiperazines: lead optimization of the second-generation antimalarial agents. J Med Chem. 2012;55:4244-73.

16. Wu T, Nagle A, Kuhen K, Gagaring K, Borboa R, Francek C, et al. Imidazolopiperazines: hit to lead optimization of new antimalarial agents. J Med Chem. 2011;54:5116-30.

17. Todeschini R, Consonni V. Molecular descriptors for chemoinformatics. 2nd ed. Weinheim: WILEY-VCH; 2009

18. Mauri A, Consonni V, Pavan M, Todeschini R. Dragon software: an easy approach to molecular descriptor calculations. MATCH Commun Math Comput Chem. 2006;56:237-48.

19. Yousefinejad S, Hemmateenejad B. Chemometrics tools in QSAR/ QSPR studies: a historical perspective. Chemom Intell Lab Syst. 2015;149:177-204.

20. Yousefinejad S, Mahboubifar M, Rasekh S. Prediction of different antibacterial activity in a new set of formyl hydroxyamino derivatives with potent action on peptide deformylase using structural information. Struct Chem. 2019;30:925-36.

21. Hawkins DM. The problem of overfitting. J Chem Inf Comput Sci. 2004;44:1-12
22. Gramatica P. External evaluation of QSAR models, in addition to crossvalidation: verification of predictive capability on totally new chemicals. Mol Inform. 2014;33:311-4.

23. Netzeva TI, Worth AP, Aldenberg T, Benigni R, Cronin MD, Gramatica P, et al. Current status of methods for defining the applicability domain of (quantitative) structure-activity relationships. Altern Lab Anim. 2005:33:155-73.

24. Sahigara F, Mansouri K, Ballabio D, Mauri A, Consonni V, Todeschini R. Comparison of different approaches to define the applicability domain of QSAR models. Molecules. 2012;17:4791-810.

25. Gramatica P. Principles of QSAR models validation: internal and external. QSAR Comb Sci. 2007;26:694-701.

26. Yousefinejad S, Honarasa F, Montaseri H. Linear solvent structure-polymer solubility and solvation energy relationships to study conductive polymer/carbon nanotube composite solutions. RSC Adv. 2015;5:42266-75.

27. Dimitrov S, Dimitrova G, Pavlov T, Dimitrova N, Patlewicz G, Niemela J et al. A stepwise approach for defining the applicability domain of SAR and QSAR models. J Chem Inf Model. 2005;45:839-49.

28. Honarasa F, Yousefinejad S, Nasr S, Nekoeina M. Structure-electrochemistry relationship in non-aqueous solutions: predicting the reduction potential of anthraquinones derivatives in some organic solvents. J Mol Liq. 2015;212:52-7.

29. Yousefinejad S, Eftekhari R, Honarasa F, Zamanian Z, Sedaghati F. Comparison between the gas-liquid solubility of methanol and ethanol in different organic phases using structural properties of solvents. J Mol Liq. 2017;241:861-9.

30. Yasri A, Hartsough D. Toward an optimal procedure for variable selection and QSAR model building. J Chem Inf Comput Sci. 2001;41:1218-27.

31. Yoo W, Mayberry R, Bae S, Singh K, He QP, Lillard JW Jr. A study of effects of multicollinearity in the multivariable analysis. Int J Appl Sci Technol. 2014:4:9.

32. Alin A. Multicollinearity. Wiley Interdiscip Rev Comput Stat. 2010;2:370-4.

\section{Publisher's Note}

Springer Nature remains neutral with regard to jurisdictional claims in published maps and institutional affiliations.
Ready to submit your research? Choose BMC and benefit from:

- fast, convenient online submission

- thorough peer review by experienced researchers in your field

- rapid publication on acceptance

- support for research data, including large and complex data types

- gold Open Access which fosters wider collaboration and increased citations

- maximum visibility for your research: over 100M website views per year

At BMC, research is always in progress.

Learn more biomedcentral.com/submissions 